

\title{
Neurourological Application of Neurogenesis and Inflammation and Pain Mechanisms of Rocuronium Bromide
}

\author{
Khae Hawn Kim (iD http://orcid.org/0000-0002-7045-8004 \\ Department of Urology, Gachon University Gil Medical Center, Gachon University of Medicine and Science, Incheon, Korea \\ E-mail: kimcho99@gilhospital.com
}

In the present issue of the International Neurourology Journal, 2 interesting topics were included. One is "Current opinion on the role of neurogenesis in the therapeutic strategies for Alzheimer disease, Parkinson disease, and ischemic stroke; considering neuronal voiding function" [1] and the other is "Rocuronium bromide inhibits inflammation and pain by suppressing nitric oxide production and enhancing prostaglandin E2 synthesis in endothelial cells" [2].

Alzheimer disease, Parkinson disease, and cerebral infarction are common neurological diseases. Most patients suffering from these disorders experience difficulty in voiding. In Alzheimer disease, urge incontinence occurs due to detrusor hyperreflexia. Urinary urgency, urinary frequency, nocturia, and urge incontinence occur complexly in patients with Parkinson disease. In patients with cerebral infarction, retention of urine caused by areflexic bladder, urinary urgency, or urinary frequency caused by detrusor hyperreflexia occurs frequently. However, there is a shortage of satisfactory treatments to control and improve neurogenic bladder induced by such neurological diseases [3,4].

Researches are currently underway in order to develop new neurogenic bladder treatments, and some researchers have reported that nerve stimulation and stem cells improve neurogenic bladder [5-7]. In order to effectively treat neurogenically dysfunctional bladder, treatments should also prevent functional deterioration of the central nervous system. Adult neurogenesis is known to generate new nerve cells in the adult hippocampal dentate gyrus, thereby sustaining the overall function of the brain by maintaining and improving learning ability and memory function. As adult neurogenesis is proven to help recover of brain damage, researches in adult neurogenesis have been quite actively for hard-to-cure diseases. Integrative adult neurogenesis researches are expected to help improve voiding difficulty, which is commonly found in such neurological diseases.

Effects of rocuronium bromide in the vascular wall were also introduced in this issue. Nondepolarizing neuromuscular blocking agent, rocuronium bromide, has been used as an adjunct for relaxation or paralysis of skeletal muscles, facilitation of endotracheal intubation, and improving surgical conditions during general anesthesia $[8,9]$. The adverse effect of rocuronium bromide is injection pain or withdrawal movement. Diverse mechanisms of the adverse effect of rocuronium bromide have been suggested to date, however, the exact mechanisms are still not proved.

The authors, demonstrated that rocuronium bromide inhibited endothelial nitric oxide synthase followed by suppressed nitric oxide (NO) production in calf pulmonary artery endothelial (CPAE) cells. Rocuronium bromide also activated cyclooxygenase-2, inducible nitric oxide synthase, and then increased prostaglandin $\mathrm{E}_{2}\left(\mathrm{PGE}_{2}\right)$ synthesis in CPAE cells. They suggested that suppressing $\mathrm{NO}$ production and enhancing PGE2 synthesis might be associated with the underlying mechanism of rocuronium bromide-induced injection pain or withdrawal movement.

Consequently, comprehensive information on adult neuro- 
genesis and comprehension of rocuronium bromide-induced inflammation and pain could help to establish the foundation for neurourology.

- Conflict of Interest: No potential conflict of interest relevant to this article was reported.

\section{REFERENCES}

1. Han MH, Lee EH, Koh SH. Current opinion on the role of neurogenesis in the therapeutic strategies for Alzheimer disease, Parkinson disease, and ischemic stroke; considering neuronal voiding function. Int Neurourol J 2016;20:276-87.

2. Baek SB, Shin MS, Han JH, Moon SW, Chang B, Jeon JW, et al. Rocuronium bromide inhibits inflammation and pain by suppressing nitric oxide production and enhancing prostaglandin $\mathrm{E}_{2}$ synthesis in endothelial cells. Int Neurourol J 2016;20:296-303.

3. Biallosterski BT, Prickaerts J, Rahnama’i MS, de Wachter S, van Koeveringe GA, Meriaux C. Changes in voiding behavior in a mouse model of Alzheimer's disease. Front Aging Neurosci 2015;7:
160.

4. Cho YS, Ko IG, Kim CJ, Kim KH. A novel intracerebral hemorrhage-induced rat model of neurogenic voiding dysfunction: Analysis of lower urinary tract function. Mol Med Rep 2015;12:2563-9.

5. Miyazato M, Kitta T, Kaiho Y, Oshiro T, Saito S, Chancellor MB, et al. Effects of duloxetine on urethral continence reflex and bladder activity in rats with cerebral infarction. J Urol. 2015;194:842-7.

6. Blanco L, Ros CM, Tarragón E, Fernández-Villalba E, Herrero MT. Functional role of Barrington's nucleus in the micturition reflex: relevance in the surgical treatment of Parkinson's disease. Neuroscience 2014;266:150-61.

7. Campeau L, Soler R, Sittadjody S, Pareta R, Nomiya M, Zarifpour $\mathrm{M}$, et al. Effects of allogeneic bone marrow derived mesenchymal stromal cell therapy on voiding function in a rat model of Parkinson disease. J Urol 2014;191:850-9.

8. Borgeat A, Kwiatkowski D. Spontaneous movements associated with rocuronium: is pain on injection the cause? $\mathrm{Br}$ J Anaesth 1997;79:382-3.

9. Bowman WC. Neuromuscular block. Br J Pharmacol 2006;147 Suppl 1:S277-86. 